\title{
The Effect of N-Fertilization on Rosmarinus Officinalis $L$. (An Upright Variety) Yield in Central Greece
}

Eleni Wogiatzi-Kamwoukou, Nickolaos Gougoulias, Zoi Papadouli, Baia Theodosiou and Kyriakos D Giannoulis Department of Agronomy Technology, Technological Educational Institute of Thessaly, T.E.I. 41110, Larisa, Greece

\begin{abstract}
The effect of three different N-fertilization levels (N1: 625, N2: 385 and N3: $770 \mathrm{~kg} \mathrm{ha}^{-1}$; where in case of N1 was used the $3-6-10+3 \mathrm{MgO}+30 \% \mathrm{OM}$ and in cases of N2-N3 the 26-0-0 fertilizers) on fresh and dry weight of the perennial Rosmarinus officinalis (upright cultivar) was investigated during the 2nd year after establishment at the Experimental Farm of the Technological Educational Institute of Thessaly in Greece (TEI; Larissa plain) in 2015. It is well documented that the crop reaches its potential yield on the third year of cultivation and continues producing biomass for as long as eight years. Complete weather data (air temperature, radiation, air humidity, precipitation) were recorded hourly in an automatic meteorological station, which was installed to the experimental farm of TEI. Upon harvest (November 3rd 2015), the crop reached a maximum fresh yield of 11.67 tons per hectare and dry yield of 4.3, respectively. The average fresh weight was 8.2, 8.4 and $8.9 \mathrm{t} \mathrm{ha}^{-1}$ and the dry weight were 2.6, 3.1 and $3.2 \mathrm{t}$ ha ${ }^{-1}$ for the N1, N2 and N3 levels, respectively. Furthermore the higher moisture content was observed in the case of N1 level (68\%). Therefore, the above data show that rosemary cultivation could be a promising alternative crop, especially in case of the consideration that average selling price of dry rosemary in Greece is $3.5 € \mathrm{~kg}^{-1}$ and the average gross income exceeds the amount of $10,000 € \mathrm{ha}^{-1}$.
\end{abstract}

Key words: Rosmarinus officinalis L., fertilization, upright variety, fresh yield, dry yield.

\section{Introduction}

Rosemary is an evergreen perennial shrub, which belongs to the class Magnoliopsida, subclass Lamiales, family of Lamiaceae or Labiate (Labiatae) which comprises up to 200 genera and about 3,500 species, and it is naturally found in all of the coastal regions of the Mediterranean Sea [1] and the genus Rosmarinus, officinalis species. The plant botanically characterized from its square stems, while leaves are opposite in pairs and arranged crosswise. Most important of all is the fragrant smell.

Generally rosemary is a plant which grows in areas where there is mild hot and cold climate. A feature of the plant is that it can be grown in lowland areas with an elevation of up to 600 meters [2]. Rosmarinus officinalis L., has been widely cultivated since antiquity as herb and garden plant, and also for its

Corresponding author: Eleni Wogiatzi-Kamwoukou, assistant professor, research field: aromatic and pharmaceutical plants. essential oil [3].

The red light affects the morphology of rosemary, the phenology as well as the essential oil. More specifically, the quantity and quality of the essential oil of rosemary which was grown in greenhouse conditions, affected by the wavelength of red light (660 nm) and dark-red (730 nm) which was applied [4]. Photoperiod is a very important factor, who irrelevant to the formation of the plant metabolic mechanism, from the production of photosynthetic carbon to determine the path that leads either to the class selection (terpenoids, phenylpropanoids) or in group selection (monoterpenes, sesquiterpenes, etc.) [5].

The temperature seems to be an important factor determining both the composition of the essential oil and the content of plant essential oil. The effects of temperature and moisture in growth, development and morphology of plants cannot easily be studied separately as it is closely related and interdependent 
environmental factors. The sum of the amount of the four main components represents the phenolic path and appears to be affected by how hot the climate is [6]. The number of flowers and their total weight was greatest at low than at high temperatures [7]. Plants adapted to hot and dry climates environments develop small leaves, wrapped and covered with a dense coat to resist the water loss from the surface [8].

Irrigation must be done depending on the precipitation of the selected region. Thus, in areas with low rainfall where plants get strong root system is necessary supplemental irrigation. In contrast, in areas with rainfall (over $500 \mathrm{~mm}$ ) and in case that the plants have fully installed, the crop can continue to develop with minimal irrigation at critical points. Specifically, the lack of water and the water stress in rosemary reduces plant growth in contrast to the proportion of the essential oil which is increased [9].

Rosemary is cultivated for green and dry drug and essential oil. The harvest period is determined by the desired product. Because the crop is perennial, harvest takes place from the second year of crop establishment and the plant goes into full production in the third year. The aroma of flowers diffused in the environment so attracted insects and as a result have better pollination and crossing of not self-pollinating plants [10].

This study was conducted in the main agricultural plain (Thessaly) to evaluate the effect of Nitrogen fertilization on the fresh and dry yield of Rosemary repens and upright (Rosmarinus officinalis) in Greece.

\section{Materials and Methods}

Rosemary upright was cultivated at the experimental Farm of TEI of Thessaly. The planting took place on 09.04.2014 and the harvest during its second year after establishment at the start of the flowering period when the concentration of essential oils maximized [11]. The effect of three different N-fertilization levels (N1: 625, N2: 385 and N3: 770 $\mathrm{kg} \mathrm{ha}^{-1}$; where in case of $\mathrm{N} 1$ was used the $3-6-10+3 \mathrm{MgO}+30 \% \mathrm{OM}$ and in cases of N2-N3 the
26-0-0 fertilizers) on fresh and dry weight of the perennial Rosmarinus officinalis (upright cultivar) was investigated during the 2nd year after establishment at the Experimental Farm of the Technological Educational Institute of Thessaly (TEI; Larissa plain) in 2015. The experiment had a randomized block design and each experimental piece had an area of 16 $\mathrm{m}^{2}$ with 28 plants. The leaves and shoots after harvesting were dried in a dark place at room temperature. To obtain the essential oil of rosemary was used the method of distillation following the below procedure. In a $500 \mathrm{~mL}$ flask placed $10 \mathrm{gr}$ of dry drug and supplement to the medium with water. Then the flask placed on the heating plate of the Clevenker device. The fresh, dry weight and the essential oil content data were analyzed using the GenStat 7th Edition statistical package.

\section{Results and Discussion}

\subsection{Soil Analysis}

The soil used for the rosemary cultivation was of low organic matter content and low salinity as it is presented in the following Table 1.

\subsection{Plant Height}

The average plant height (Fig. 1) during the first 15 days after planting was higher in N3 treatment.

In the coming 45 days, the average height showed no significant differences in the different fertilization levels $(p>0.05)$. At the 75th day from the planting, the average height of plants (Table 2) showed no statistically significant difference in relation to the fertilization levels $(\mathrm{p}>0.05)$.

\subsection{Fresh Yield}

Into Fig. 2 is illustrated the average fresh weight of rosemary as it is affected from the three different used nitrogen levels and fertilizer types. There was not found any statistical significant difference (Table 3) between the used nitrogen levels. It was found that the use of the N1 type and level of fertilizer (625 kg ha ${ }^{-1}$ 
Table 1 Chemical properties of the Rosemary field experiment.

\begin{tabular}{lll}
\hline \multirow{2}{*}{ Property } & Soil depth $(0-25) \mathrm{cm}$ & Soil depth $(25-50) \mathrm{cm}$ \\
\cline { 2 - 3 } & Before transplanting & After harvest \\
\hline Texture & Loam & Loam \\
\hline pH (1part soil:5parts $\left.\mathrm{H}_{2} \mathrm{O}\right)$ & $7.81 \pm 0.16$ & $7.82 \pm 0.16$ \\
Electrical conductivity, extract $\left(\mathrm{dSm}^{-1}\right)$ & $0.11 \pm 0.01$ & $0.10 \pm 0.01$ \\
(1part soil:5parts $\left.\mathrm{H}_{2} \mathrm{O}\right)$ & $0.93 \pm 0.05$ & $0.77 \pm 0.04$ \\
Organic matter $(\%)$ & $44.8 \pm 4.07$ & $41.3 \pm 3.44$ \\
N-inorganic $\left(\mathrm{mg} \mathrm{kg}^{-1}\right)$ & $373.3 \pm 7.45$ & $314.5 \pm 7.86$ \\
K-exchangeable $\left(\mathrm{mg} \mathrm{kg}^{-1}\right)$ & $13.1 \pm 1.87$ & $10.2 \pm 1.46$ \\
$\left.\mathrm{P}-\mathrm{Olsen}_{(\mathrm{mg} \mathrm{kg}}^{-1}\right)$ & $0.63 \pm 0.07$ & $1.04 \pm 0.12$ \\
$\mathrm{CaCO}_{3}(\%)$ &
\end{tabular}

* Data represent average means and SE deviation. (n) $=4$.

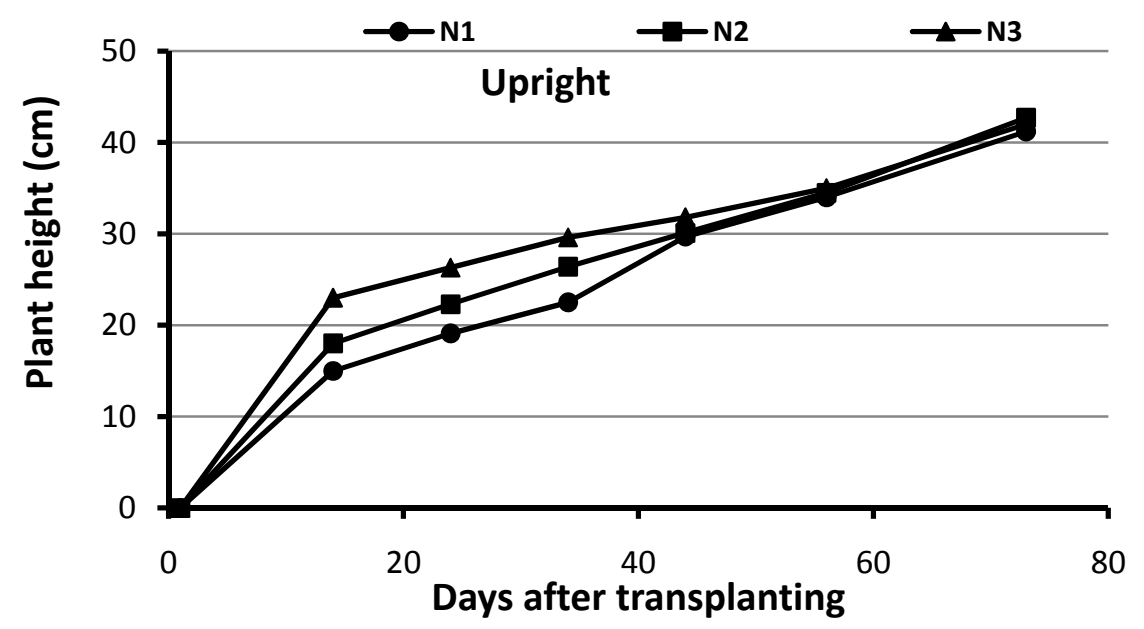

Fig. 1 Average height of Rosmarinus officinalis as affected of the three different nitrogen levels and fertilizer types.

Table 2 Average plant at the 75th day after transplanting.

\begin{tabular}{ll}
\hline Treatments & Rosemary \\
\hline Fertilization levels & Plant height $(\mathrm{cm})$ \\
\hline N1 & $41.7 \pm 2.09$ \\
N2 & $42.7 \pm 2.25$ \\
N3 & $42.0 \pm 2.17$ \\
\hline
\end{tabular}

* Data represent average means and SE deviation. $(n)=4$.

from 3-6-10+3MgO+30\% OM) which was almost the double quantity of N2 (385 $\mathrm{kg} \mathrm{ha}^{-1}$ from 26-0-0) produced an average yield of $8.19 \mathrm{t} \mathrm{ha}^{-1}$, yield almost the same with the produced in case of $\mathrm{N} 2$ level (8.36 $\mathrm{t}$ $\mathrm{ha}^{-1}$ ). Moreover by increasing the quantity of the 26-0-0 to the double dose the average yield increased only by $0.54 \mathrm{t} \mathrm{ha}^{-1}$.

\subsection{Dry Yield}

Fig. 3 illustrates the average dry weight of rosemary as it is affected from the three different nitrogen levels and fertilizer types. There was found no statistical difference (Table 3) for the examined factor. Verified the results of fresh weight, it was found that by increasing the quantity of the 26-0-0 to the double dose (N2 vs. N3) the average dry yield increased only by $0.15 \mathrm{tha}^{-1}$. In case of the $\mathrm{N} 1$ the average dry yield was $2.64 \mathrm{t} \mathrm{ha}^{-1}$.

Therefore, it could be assumed that N1 type is not delivering the expected results, and rosemary is a plant 


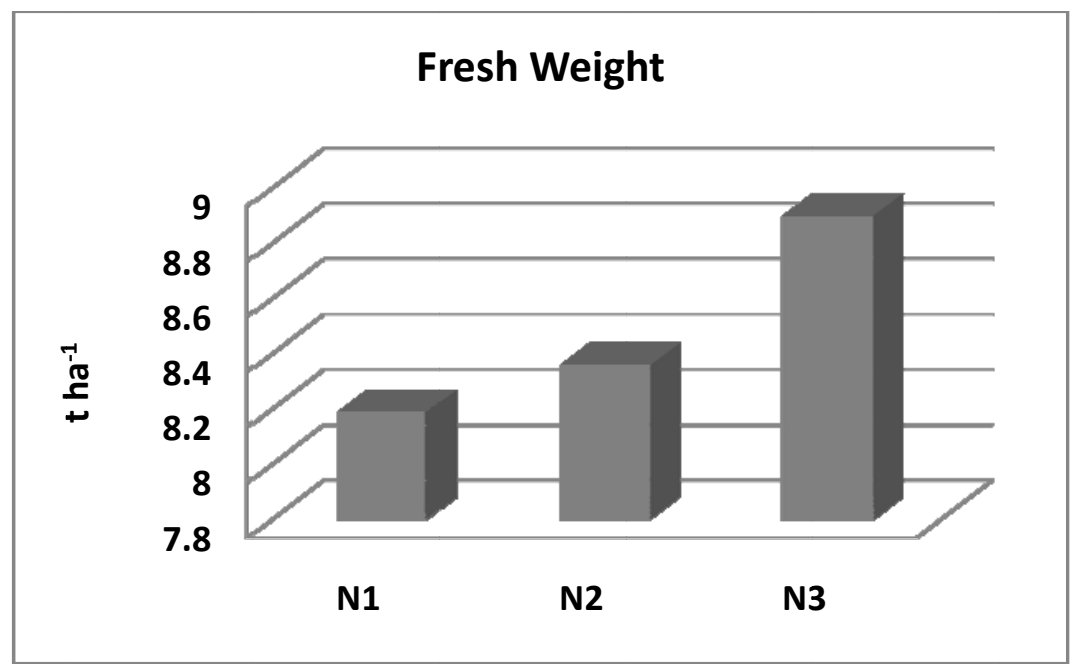

Fig. 2 Fresh weight of Rosmarinus officinalis as affected of the three different nitrogen levels and fertilizer types.

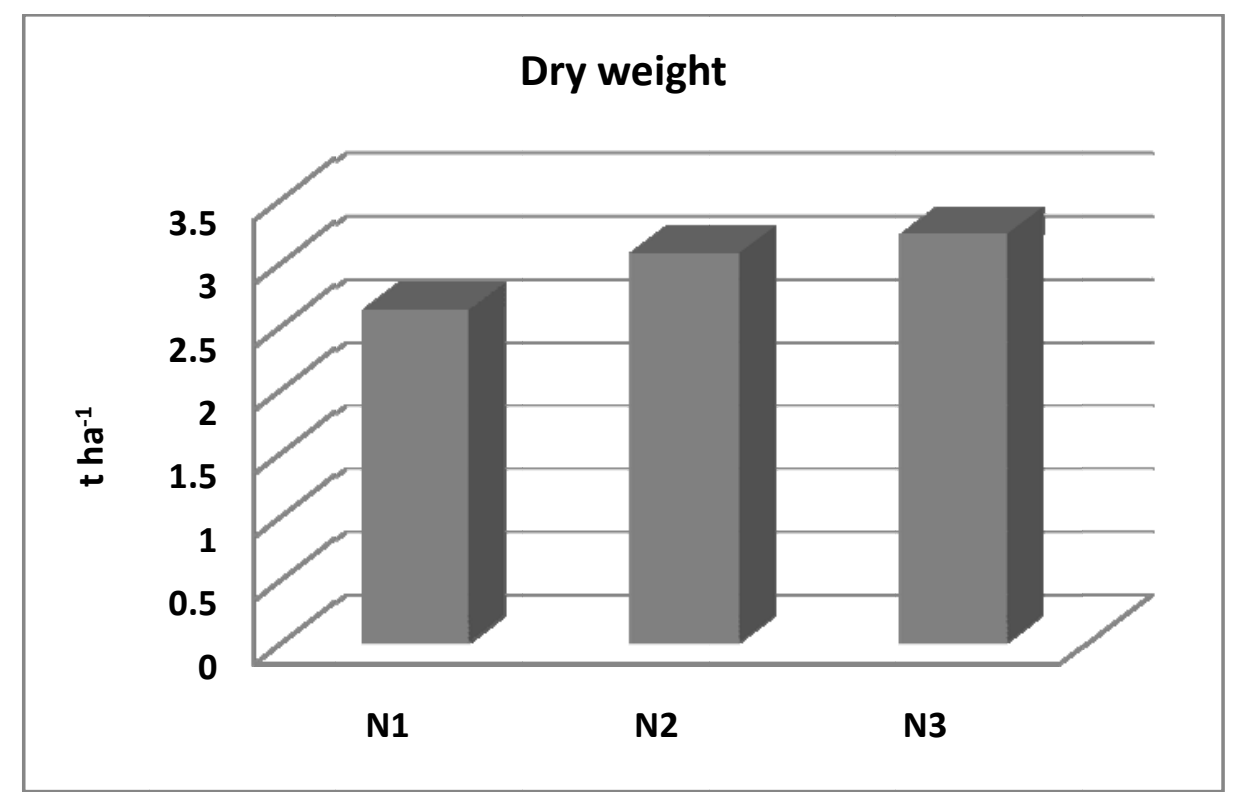

Fig. 3 Dry weight of Rosmarinus officinalis as affected of the three different nitrogen levels and fertilizer types.

Table 3 Fresh and dry weight of Rosmarinus officinalis under different nitrogen levels and fertilizer types.

\begin{tabular}{lll}
\hline Rosmarinus officinalis & $\begin{array}{l}\text { Fresh weight } \\
\left(\mathrm{t} \mathrm{ha}^{-1}\right)\end{array}$ & $\begin{array}{l}\text { Dry weight } \\
\left(\mathrm{t} \mathrm{ha}^{-1}\right)\end{array}$ \\
\hline Nitrogen levels & & 2.64 \\
\hline N1 (625 kg ha-1 $3-6-10+3 \mathrm{MgO}+30 \% \mathrm{OM})$ & 8.19 & 3.09 \\
$\mathrm{~N} 2\left(26-0-0 ; 385 \mathrm{~kg} \mathrm{ha}^{-1}\right)$ & 8.36 & 3.24 \\
N3 $\left(26-0-0 ; 770 \mathrm{~kg} \mathrm{ha}^{-1}\right)$ & 8.90 & $\mathrm{~ns}^{*}$ \\
LSD $_{0.05}$ & $\mathrm{~ns}^{*}$ & 15.0 \\
CV \% & 17.6 & \\
\hline
\end{tabular}

ns: non significant difference. 
Table 4 Essential oil content of Rosmarinus officinalis under different nitrogen levels and fertilizer types.

\begin{tabular}{ll}
\hline Treatments & Essential oil (mL/10 gr) \\
\hline Fertilization levels & \\
\hline N1 & $0.1092 \mathrm{a}$ \\
N2 & $0.1164 \mathrm{~b}$ \\
N3 & $0.1228 \mathrm{~b}$ \\
LSD 0,05 & 0.00668 \\
CV $(\%)$ & 12.3 \\
\hline
\end{tabular}

* Dancan criterion: a, b.

of low nitrogen requirements, since by increasing the dose in double, the yield of the plant does not perform statistical significant differences.

In comparison with previous studies in six different locations [12] ranged between $0.55 \mathrm{t} \mathrm{ha}^{-1}$ to $0.82 \mathrm{t} \mathrm{ha}^{-1}$, yield which is lower than the half of the produced in this study. In contrary, it was reported [13] a yield $7.82 \mathrm{t} \mathrm{ha}^{-1}$ during the first year after establishment and reached up to $22.12 \mathrm{t} \mathrm{ha}^{-1}$ for the year after. This high difference may best be explained by ecological conditions and different crop age. In a two year trial Sonmez [14] yielded 1.23-2.18 $\mathrm{t} \mathrm{ha}^{-1}$ for two continuous years, which results are in agreement with those that were found. Furthermore the higher moisture content was observed in the case of N1 level and fertilizer type (68\%).

\subsection{Essential Oil Content}

The essential oil production was counted in mL/10 gr dry drug. Table 4 shows the statistical analysis of the essential oil production, where it is clearly indicated that there is a statistically significant difference between the zero fertilization (N1) and the other two fertilization levels (N2 and N3).

\section{Conclusions}

The general conclusion that was found from this study is that Rosmarinus officinalis is a low nitrogen requirement crop, where by doubling the fertilization dose there was only observed constant voltage supremacy. The N-fertilization level of $385 \mathrm{~kg} \mathrm{ha}^{-1}$ using the 26-0-0 fertilizer type produced an average dry yield of $3.09 \mathrm{t} \mathrm{ha}^{-1}$ setting this level as the best choice for farmers if someone will take in mind the fertilization costs. Finally, the unfertilized treatments of Rosemary produced significant higher amounts of essential oil, demonstrating the inverse effect of fertilization effect. Therefore, the above data show that rosemary cultivation could be a promising alternative crop, especially in case of the consideration that average selling price of dry rosemary in Greece is $3.5 € \mathrm{~kg}-1$ and the average gross income exceeds the amount of $10,000 € \mathrm{ha}^{-1}$, but further investigation is necessary to be conducted as to be able to lead to safer conclusions.

\section{References}

[1] do Amaral Franco, J., and da Rocha Afonsa, M. L. 1972. “Rosmarinus L.” In Flora Europaea, Diapensiaceae to Myoporaceae, edited by Tutin, T. G., Heywood, V. H., Burges, N. A., Moore, D. M., Valentine, D. H., Walters, S. M., and Webb, D. A., Vol. 3. Cambridge: Cambridge University Press, 187.

[2] Dordas, X. 2012. Aromatic and Medicinal Plants. Thessaloniki: Modern Education Publications.

[3] Porte, A., Godoy, R., Lopes, D., Koketsu, M., Torquilho, S. L., and Torquilho, H. 2000. "Essential Oil of Rosmarinus Officinalis L. (rosemary) from Rio de Janeiro.” Brazil. J. Essent. Oil Res. 12: 577-80.

[4] Mulas, G., Gardner, Z., and Craker, L. E. 2006. "Effect of Light Quality on Growth and Essential Oil Composition in Rosemary.” In First International Symposium on the Labiatae: Advances in Production, Biotechnology and Utilisation. Italy International Society for Horticultural Science, 427-732.

[5] Sangwan, N. S., Farooqi, A. H. A., Shabih, F., and Sangwan, R. S. 2001. "Regulation of Essential Oil Production in Plants.” Plant Growth Regul 34: 3-21.

[6] Vokou, D., Kokkini, S., and Bessiere, J. M. 1993. "Geographic Variation of Greel Oregano (Origanum Vulgare ssp. Hirtum) Essential Oils.” Biochem, Systematics and Ecology 21 (2): 287-95. 
[7] Putievsky, E., Dudai, N., and Ravid, U. 1997. "Cultivation, Selection and Conservation of Oregano Species in Israel.” Edited by Padulosi, G. In Proceedings of the IPGRI International Workshop on Oregano, May 8-12, 1996, Valenzano, Bari, Italy, 102-09.

[8] Fitter, A. H., and Hay, R. K. M. 1987. Environmental Physiology of Plants. London: Academic Press.

[9] Leithy, S., El-Meseiry, T. A., and Abdallah, E. F. 2006. "Effect of Biofertilizer, Cell Stabilizer and Irrigation Regime on Rosemary Herbage Oil Yield and Quality.” Journal of Applied Sciences Research 2 (10): 773-9.

[10] Mahmoud, S. S., and Croteau, R. B. 2002. "Strategies for Transgenic Manipulation of Monoterpene Biosynthesis in Plants.” Trends plant Science 7: 366-73.

[11] Marquard, R., and Kroth, E. 2001. Anbau und Qualitätsanforderungen ausgewählter Arzneipflanzen,
(Cultivation and Quality Requirements of Selected Medicinal Plants) Agrimedia, Bergen Dumme.

[12] Gurbuz, B., Bagdat, R. B., Uyanik, M., and Afshar Pour Rezaeieh, K., 2015. Rosemary (Rosmarinus officinalis L.) Cultivation Studies under Ankara Ecological Conditions. Industrial Crops and Products. (article in press)

[13] Kirpik, M. 2005. "Evaluating Qualitative Rosemary (Rosmarinus officinalis L.) Lines Growing in Arid soils of Cukurova Region.” Ph.D. thesis, Cukurova University Institute of Science, Adana, 97.

[14] Sonmez, C. 2007. "Determination of Some Agronomic and Technological Properties in Different Originated of Rosemary (Rosmarinus officinalis L.).” M.Sc. thesis. Cukurova University, Institute of Science, Bornova-Izmir, 66. 